\title{
Comparison of availability and plasma clearance rates of $\beta$-hydroxy- $\beta$-methylbutyrate delivery in the free acid and calcium salt forms
}

\author{
John C. Fuller $\mathrm{Jr}^{1}$, Rick L. Sharp ${ }^{2}$, Hector F. Angus ${ }^{2}$, Paul Y. Khoo ${ }^{2}$ and John A. Rathmacher ${ }^{1,3 *}$ \\ ${ }^{1}$ Metabolic Technologies Inc., Iowa State University Research Park, Ames, IA 50010, USA \\ ${ }^{2}$ Department of Kinesiology, Iowa State University, Ames, IA 50010, USA \\ ${ }^{3}$ Department of Animal Science, Iowa State University, Ames, IA 50010, USA
}

(Submitted 22 February 2015 - Final revision received 14 July 2015 - Accepted 17 July 2015 - First published online 16 September 2015)

\section{Abstract}

$\beta$-Hydroxy- $\beta$-methylbutyrate (HMB), a leucine metabolite, has long been supplemented as a Ca salt (Ca-HMB) to increase strength and performance gains with exercise and to reduce recovery time. Recently, the free acid form of HMB (HMB-FA) has become commercially available in capsule form (gelcap). The current study was conducted to compare the bioavailability of HMB using the two commercially available capsule forms of HMB-FA and Ca-HMB. We also compared the pharmacokinetics of each form when administered mixed in water. Ten human subjects (five male and five female) were studied in a randomised crossover design. There was no significant sex by treatment interaction for any of the pharmacokinetic parameters measured. HMB-FA administered in capsules was more efficient than Ca-HMB capsule at HMB delivery with a $37 \%$ increase in plasma clearance rate (74.8 (SEM 4.0) $v .54 .5$ (SEM 3.2) ml/min, $P<0.0001)$ and a $76 \%$ increase in peak plasma HMB concentration (270.2 (SEM 17.8) $v$. 153.9) (SEM 17.9) $\mu \mathrm{mol} / \mathrm{l}$, $P<0.006)$, which was reached in one-third the time $(P<0.009)$. When HMB-FA and Ca-HMB were administered in water, the differences still favoured HMB-FA, albeit to a lesser degree. Plasma HMB with HMB-FA administered in water was greater during the early phase of absorption (up to 45 min postadministration, $P<0.05$ ); this resulted in increased AUC during the first $60 \mathrm{~min}$ after administration, when compared with Ca-HMB mixed in water $(P<0.03)$. In conclusion, HMB-FA in capsule form improves clearance rate and availability of HMB compared with Ca-HMB in capsule form.

\section{Key words: $\beta$-Hydroxy- $\beta$-methylbutyrate: Free acid form of hydroxy- $\beta$-methylbutyrate: Calcium salt of hydroxy- $\beta$-methylbutyrate:} Gelcaps: Capsules: Clearance

The leucine metabolite $\beta$-hydroxy- $\beta$-methylbutyrate (HMB) has a long history of use as a nutritional supplement for enhancing recovery, and for increasing strength, power, aerobic performance and lean body mass with exercise ${ }^{(1-5)}$. HMB improves muscle protein balance by decreasing muscle protein breakdown and by increasing muscle protein synthesis ${ }^{(6-11)}$, resulting in reduced muscle damage and faster and improved recovery ${ }^{(3,12,13)}$. These benefits with HMB to improve muscle performance with vigorous exercise have generally been achieved with the Ca salt of HMB (Ca-HMB) administered in capsule form. However, as shown in previous studies, and confirmed by the findings of the current study, peak plasma levels of $\mathrm{HMB}$ are not reached until approximately 120 min after ingestion of $\mathrm{Ca}-\mathrm{HMB}$, which makes it inconvenient for scheduling exercise sessions to coincide with peak plasma HMB levels ${ }^{(14,15)}$. In this study, we show that the time to peak HMB level decreased by two-thirds when HMB was delivered as the free acid in capsule form (HMB-FA), thus making it more convenient to time peak HMB level with exercise.

The anabolic stimulus of exercise results in an increase in muscle protein synthesis in as little as $1 \mathrm{~h}$ postexercise ${ }^{(16)}$, and it can persist for up to $48 \mathrm{~h}$ postexercise ${ }^{(17)}$. These anabolic events are also accompanied by depletion of muscle energy stores in the form of glycogen, resulting in decreased exercise intensity, and associated with increased muscle damage $^{(18-20)}$. The changes have been attributed to increased skeletal muscle AMP-activated protein kinase activity and reduced phosphorylation of $4 \mathrm{E}-\mathrm{BP} 1$ in the mTOR pathway, as occurs with resistance exercise ${ }^{(16)}$. HMB supplementation has been shown to increase phosphorylation of 4E-BP1 in human muscle ${ }^{(11)}$, prompting us to hypothesise that HMB as HMB-FA would offer a more convenient delivery form resulting in an improved anabolic effect of HMB on muscle protein synthesis and diminishing protein breakdown.

Other metabolic effects of HMB have been demonstrated in animal models. Turkeys fed HMB during the last 15 weeks of rearing had increased bone density and strength and an increase in some plasma amino acids including the branched-chain amino acids ${ }^{(21)}$. Tatara et al. $^{(22)}$ also demonstrated increased growth and bone density, and increased growth hormone (GH) and insulin-like growth factor-1 (IGF-1),

Abbreviations: Ca-HMB, calcium salt of HMB; HMB, $\beta$-hydroxy- $\beta$-methylbutyrate; HMB-FA, free acid form of HMB.

* Corresponding author: Dr J. A. Rathmacher, fax +1 5152960908 , email rathmacher@mti-hmb.com 
in offspring of sows fed HMB for the final 2 weeks of pregnancy; increased bone density and plasma amino acid concentrations in pigs with fundectomy-induced osteopaenia ${ }^{(23)}$; and improved somatotrophic axis and accelerated bone metabolism in lambs fed HMB for the first $21 \mathrm{~d}$ after birth ${ }^{(24)}$. The improvement in somatotrophic axis function was further demonstrated in rats when chronic HMB administration was shown to stimulate the GH/IGF-1 axis ${ }^{(25)}$. Recently, HMB supplementation was shown to enhance the exercise-stimulated increase in GH and IGF-1 response in humans, similar to what the previous studies in animals had demonstrated ${ }^{(26)}$.

The pharmacokinetics of orally ingested $\mathrm{Ca}-\mathrm{HMB}$ in capsules were originally described by Vukovich et $a l^{(14)}$ and showed a time to peak plasma level of HMB of $2 \mathrm{~h}$ after a $1 \mathrm{~g}$ dosage. Recently, Fuller et $a l^{(15)}$ demonstrated that HMB-FA gel form increased plasma HMB concentrations in a shorter period of time (30-40 min) with a greater blood clearance rate of HMB compared with the Ca-HMB capsule. A recent 12-week exercise study by Wilson et al. ${ }^{(27)}$ used these favourable advantages to test the efficacy of HMB-FA administered $30 \mathrm{~min}$ before exercise in a periodised training programme and showed increased strength, lean body mass gain and muscle power in a highly trained athlete population $^{(27)}$, demonstrating the importance of dosage timing and peak levels of $\mathrm{HMB}$ for maximisation of exercise benefits. The current human study was thus designed to compare the pharmacokinetics of the current commercially available delivery form of Ca-HMB in a capsule and compared this with the newly designed delivery form of HMB-FA in a gelcap. Our results confirmed the previous findings of Fuller et $a l .{ }^{(15)}$ and showed that HMB-FA had superior bioavailability in humans as assessed by blood levels, and improved clearance.

\section{Methods}

\section{Human subjects}

We performed a randomised crossover study consisting of five men and five women (aged 21-32 years). The study was conducted according to the guidelines laid down in the Declaration of Helsinki, and all procedures involving human subjects were approved by the Iowa State University Institutional Review Board. Written informed consent was obtained from all subjects before participation. The study was listed on ClinicalTrials.gov (NCT01914952, https://clinicaltrials. gov). The subjects were not currently taking amino acid, protein or HMB supplements.

\section{Treatments}

The treatments were given to each subject in random order with at least a $48 \mathrm{~h}$ washout period between treatments. The treatments were as follows: (1) Ca-HMB in a commercial gelatin capsule (Optimum Nutrition); (2) HMB-FA capsule (gelcap) (Capsugel); (3) HMB-FA as a gel as previously described ${ }^{(15)}$; (4) Ca-HMB mixed in water or (5) HMB-FA mixed in water. All treatments delivered $0 \cdot 8 \mathrm{~g}$ of HMB orally, confirmed by
HPLC analysis, and were given with $355 \mathrm{ml}$ of water. Although the $\mathrm{pH}$ of the free acid itself is $<3$, this is similar to the $\mathrm{pH}$ of the stomach. For the treatments used in this study, the free acid was given either in capsule form, a buffered gel form or as a dilute solution in water. In contrast, the Ca-HMB is neutral to slightly alkaline when in solution. None of the participants reported any oesophageal or gastrointestinal irritations with any of the treatment forms of HMB. For the capsule treatments, samples of the capsules were sent to an independent laboratory and tested for dissolution times (Eurofins). Because of the nature of the various treatments, the study could not be fully blinded.

\section{Study design}

All studies were conducted after a 10- to 12-h overnight fast. Subjects arrived at the laboratory in the morning, and an intravenous catheter was inserted into a forearm vein using sterile procedures. A preingestion blood sample, of approximately $7 \mathrm{ml}$, was drawn. The treatment was then consumed over approximately a 2 min period, and additional blood samples (7 ml) were taken at 2, 5, 10, 15, 25, 35, 45, 60, 90, 120, 180, 360 (6 h), 720 (12 h) and 1440 (24 h) min after the ingestion of the supplement; $24 \mathrm{~h}$ urine collection was also obtained. Plasma and urine samples were stored at $-80^{\circ} \mathrm{C}$ until later analyses of HMB. Serum and blood samples at times 0 and $1440 \mathrm{~min}$ were analysed by a commercial laboratory (LabCorp.) for glucose, uric acid, blood urea nitrogen, creatinine, $\mathrm{Na}, \mathrm{K}, \mathrm{Cl}, \mathrm{Ca}, \mathrm{CO}_{2}, \mathrm{P}$, protein, albumin, globulin, total bilirubin, alkaline phosphatase, estimated glomerular filtration rate (eGFR), creatine kinase, lactate dehydrogenase, aspartate aminotransferase, alanine aminotransferase, $\gamma$-glutamyl transpeptidase, Fe, TAG, HDL, LDL, VLDL and cholesterol; a complete blood count was also performed. Subjects completed a brief health questionnaire to report any physical symptoms (such as nausea, headache and so on) they may have experienced during the experiment.

After the $180 \mathrm{~min}$ blood sampling, each subject was provided with a standardised lunch (1673.6-2092 kJ (400-500 kcal)), which was consumed at approximately $240 \mathrm{~min}$ postingestion; the subjects returned to the laboratory for the $720 \mathrm{~min}$ blood sample. Each subject was then instructed to eat a normal evening meal before 22.00 hours. Subjects were also instructed to refrain from any strenuous physical activity or exercise during each testing period, and diet and activity patterns were to be replicated for each treatment testing period. Subjects reported back to the laboratory the following morning for the fasted $1440 \mathrm{~min}$ blood sample. Urine collection containers were provided, and subjects collected all urine produced during the $24 \mathrm{~h}$ experimental period. The urine was stored refrigerated when possible.

\section{Plasma and urine $\beta$-hydroxy- $\beta$-methylbutyrate analysis}

The plasma and urine HMB were analysed as previously described using GC/MS ${ }^{(28)}$. Briefly, HMB in the free acid form is quantified from standards using $\mathrm{d}_{6}$-HMB as an internal standard. This method has a CV of approximately $4 \cdot 1 \%$. 


\section{Statistical analysis and calculations}

The AUC was calculated for each subject using the trapezoidal method that sums the area above the baseline ${ }^{(29)}$. The following equations were used in the calculation of the half-life of plasma HMB:

$$
\begin{gathered}
K_{\mathrm{el}}=\frac{\ln \left(C_{\text {peak }}\right)-\ln \left(C_{\text {trough }}\right)}{T_{\text {interval }}}, \\
t_{1 / 2}=\frac{0.693}{K_{\mathrm{el}}} .
\end{gathered}
$$

The peak plasma concentration was the highest HMB concentration at a measured time point for each subject and was used for $C_{\text {peak. }}$. Trough concentrations, $C_{\text {trough }}$, were the concentrations measured at $12 \mathrm{~h}$, which were not significantly different from baseline concentrations. The $T_{\text {peak }}$ was the time at which $C_{\text {peak }}$ was measured for each subject and $T_{\text {interval was }}$ $12 \mathrm{~h}$ (time at $C_{\text {trough }}$ ) minus $T_{\text {peak }}$. The extracellular fluid compartment was assumed to be $20 \%$ of body weight. $V_{d}$ was calculated using equation (3) below ${ }^{(30)}$. The plasma clearance of HMB was calculated by multiplying the extracellular fluid compartment, $V_{d}$, by the elimination constant, $K_{\mathrm{el}}$, as shown in equation $(4)^{(31)}$.

$$
\begin{gathered}
V_{d}=\operatorname{Body} \text { weight }(0 \cdot 20), \\
\text { Clearance }=V_{d}\left(K_{\mathrm{el}}\right) .
\end{gathered}
$$

The data for comparable treatments were analysed using a crossover design with the general linear models (GLM) procedure in $S A S^{(32)}$. A priori power analysis ( $G^{*}$ Power, version 3.1.7) was completed based on our previously published pharmacokinetic study ${ }^{(15)}$. Assuming a similar degree of variability, a power analysis indicated that ten subjects were required to detect a $P$ value of 0.05 at a power of 0.90 in a crossover designed study. A repeated-measures polynomial model was used for the timed sampling of plasma HMB, and the model included subject, treatment order, treatment main effects and time by treatment interaction where appropriate. For other parameters, Proc GLM was used with subject, treatment order and treatment main effects included in the model, and the $P$ values are reported for the treatment main effect. Although the study was neither designed nor powered to detect sex differences, sex by treatment interaction was determined by GLM. In addition, the main effects of Ca-HMB and HMB-FA when given in water and by capsule were determined using GLM and least square means, and these data are shown in online Supplementary Table S3. Statistical significance was determined for $P<0.05$.

\section{Results}

\section{Subject characteristics}

Subject characteristics of the five male and five female subjects are shown Table 1. The average age of the subjects was $25 \cdot 1$ (SEM 1.0) years and the average weight and BMI were $69 \cdot 1$ (sEm $3 \cdot 1$ ) $\mathrm{kg}$ and 23.0 (sEM 0.8 ) kg, respectively. The male subjects had greater body weights $(P<0.05)$ and BMI $(P<0.05)$

\begin{tabular}{|c|c|c|c|}
\hline & Mean & & SEM \\
\hline \multicolumn{4}{|l|}{$\operatorname{Sex}(n)$} \\
\hline Male/female & & $5 / 5$ & \\
\hline Age (years) & $25 \cdot 1$ & & $1 \cdot 0$ \\
\hline \multicolumn{4}{|l|}{ Body weight $(\mathrm{kg})$} \\
\hline All & $69 \cdot 1$ & & 3.1 \\
\hline Female & $64 \cdot 3$ & & $3 \cdot 0$ \\
\hline Male & 73.8 & & 4.9 \\
\hline \multicolumn{4}{|l|}{ BMI $\left(\mathrm{kg} / \mathrm{m}^{2}\right)$} \\
\hline All & 23.0 & & 0.8 \\
\hline Female & 21.9 & & 0.8 \\
\hline Male & $24 \cdot 2$ & & $1 \cdot 3$ \\
\hline
\end{tabular}
than the female subjects; however, there were no significant sex
Table 1. Subject descriptors (Mean values with their standard errors)

by treatment interactions for any of the pharmacokinetic parameters measured, even though all subjects were administered the same HMB dose.

Free acid form of $\beta$-hydroxy- $\beta$-methylbutyrate gel kinetics

The HMB-FA gel treatment in the present study showed similar pharmacokinetics as we had previously shown ${ }^{(15)}$. HMB-FA in a gel had no comparator in the current study. The $C_{\text {peak }}$ was 261.7 (SEM 15.0) $\mu \mathrm{mol} / \mathrm{l}$ at 35.5 (SEM 4.0) min postadministration. The half-life of HMB delivered in the gel form was 2.24 (SEM 0.10) $\mathrm{h}$ and the AUC was 54.1 (SEM 3.1) $\mu \mathrm{mol} / \mathrm{l} \times 1440$ min. The clearance from plasma was 71.7 (SEM 3.6 ) $\mathrm{ml} / \mathrm{min}$, and 24.6 (SEM 4.4 ) \% of the dosage was excreted in urine over the 24 h study.

Acute $\beta$-hydroxy- $\beta$-methylbutyrate kinetics for capsule and water administration

The $3 \mathrm{~h}$ plasma HMB pharmacokinetics for subjects administered the HMB-FA and Ca-HMB capsule treatments are shown in Fig. 1(a). Compared with Ca-HMB capsules, HMB-FA administration in capsules resulted in significantly greater plasma levels at all time points from 15 to $120 \mathrm{~min}$ after administration $(P<0.001$ at $15,25,35,45,60$ and $90 \mathrm{~min}$ and $P<0.05$ at $120 \mathrm{~min})$. The $180 \mathrm{~min}$ AUC was $75 \%$ greater $(P<0.001)$ for the HMB-FA in capsule form. In addition, administration of HMB-FA in capsule form resulted in $76 \%$ greater peak levels $(P<0.006)$ in one-third the time $(P<0.009)$. The dissolution time of the capsules could not account for these results; it was 13 min for the HMB-FA capsules and 5 min for the $\mathrm{Ca}-\mathrm{HMB}$ capsules, thus favouring the release of $\mathrm{Ca}-\mathrm{HMB}$ from the capsules.

Fig. 1(b) shows the $3 \mathrm{~h}$ plasma $\mathrm{HMB}$ pharmacokinetics for the administration of HMB-FA and Ca-HMB when mixed in water. Administration of HMB-FA in water resulted in greater plasma HMB levels at 15, 25, 35 and $45 \mathrm{~min}(P<0.05,0 \cdot 001$, 0.004 , and $P<0.05$, respectively). The inset shows that HMB-FA administered in water had a significantly greater AUC during the first hour of administration $(P<0.03)$. Compared with $\mathrm{Ca}-\mathrm{HMB}$ administered in water, the $C_{\text {peak }}$ tended to be greater for 
(a)

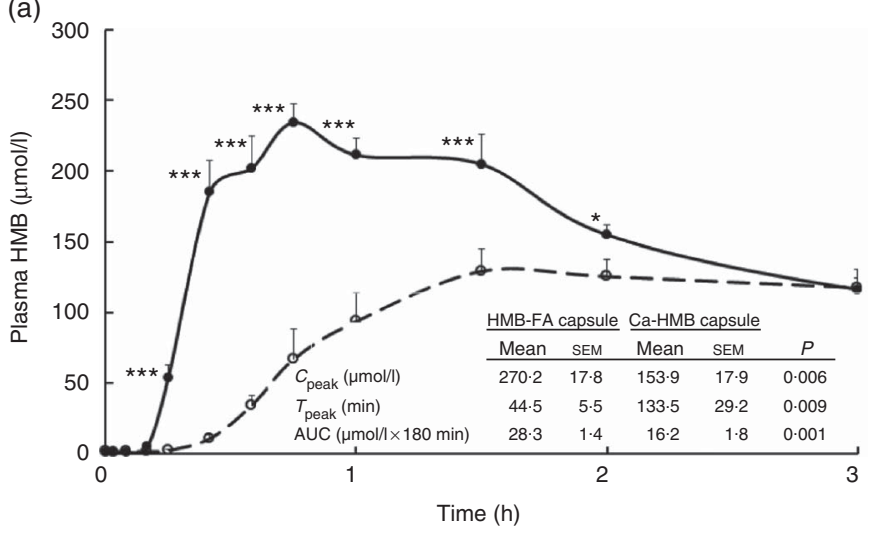

(b)

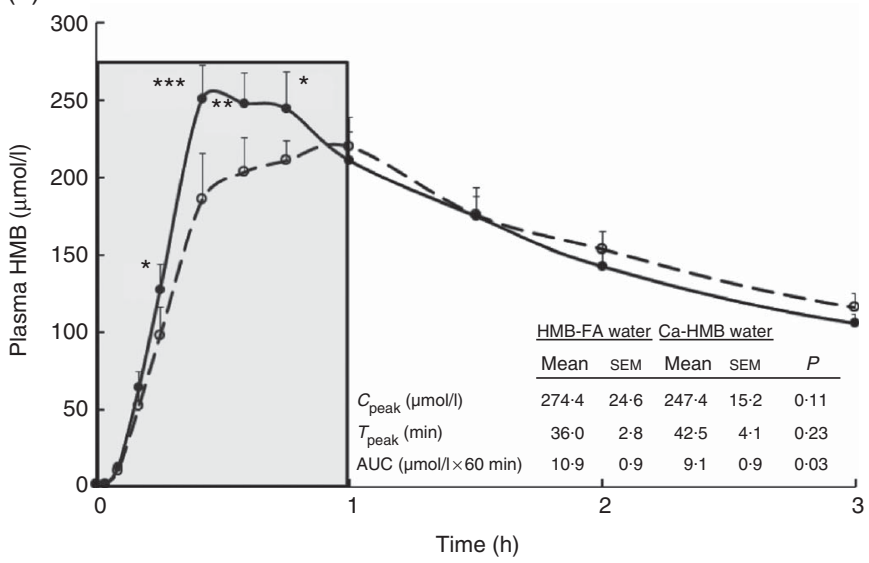

Fig. 1. (a) The $3 \mathrm{~h}$ plasma levels of $\beta$-hydroxy- $\beta$-methylbutyrate (HMB) after administration of either free acid form of HMB (HMB-FA) gelcaps (-e-) or Ca salt of HMB (Ca-HMB) capsule (- - -). (b) The $3 \mathrm{~h}$ plasma levels of HMB after administration of either HMB-FA mixed in water (-๑-) or Ca-HMB mixed in water (- -o-). All treatments contained $0.8 \mathrm{~g}$ of HMB. Values are means with their standard error of means for five men and five women. Significance between the treatments is indicated as follows: ${ }^{*} P<0.05$; ${ }^{*} P<0.004$; and ${ }^{* * *} P<0.001$. The inset table shows the peak concentration reached $\left(C_{\text {peak }}\right)$, time to reach peak concentration $\left(T_{\text {peak }}\right)$ and AUC. The $P$ value indicated is for differences between the treatment means.

HMB-FA in water, whereas the $T_{\text {peak }}$ level was not different between the HMB-FA and Ca-HMB treatments.

\section{$24 h$-hydroxy- $\beta$-methylbutyrate kinetics for capsule and water administration}

Fig. 2(a) shows the $24 \mathrm{~h}$ plasma HMB levels in subjects given either Ca-HMB or HMB-FA in capsule form. As shown in the inset, the HMB-FA capsule administration resulted in a $37 \%$ increased clearance of HMB from plasma $(P<0 \cdot 0001)$, resulting in a $29 \%$ decrease in half-life $(P<0.0003)$. The $24 \mathrm{~h}$ AUC for $\mathrm{HMB}$ and for urinary excretion rates were the same for both forms.

Similarly, Fig. 2(b) shows the $24 \mathrm{~h}$ plasma HMB levels in subjects given either Ca-HMB or HMB-FA mixed in water. We noted significant differences in plasma HMB levels during the first hour, with no further observed differences during the $24 \mathrm{~h}$ measurement period. As seen in the inset, there were also no differences observed for plasma HMB half-life, clearance rates or AUC over the $24 \mathrm{~h}$ measurement period. In addition, $24 \mathrm{~h}$ urinary excretion as a percentage of the initial dose was the same for both treatments.

\section{Blood chemistry and haematology}

There were no untoward effects of the treatments on blood chemistries or haematology and the data are presented in online Supplementary Tables S1 and S2.

\section{Discussion}

In this study, we tested the human pharmacokinetics of the two commercially available forms of HMB, used for the promotion of muscular strength and mass. Our results demonstrate that, irrespective of the capsule delivery form used, HMB-FA is more readily available and has a higher clearance rate than $\mathrm{Ca}-\mathrm{HMB}$ (Fig. 2(a)), indicative of higher efficiency and faster utilisation. All human studies to date have consistently demonstrated the superiority of the HMB-FA form to reach a higher HMB plasma peak in a much shorter time than the Ca-HMB form, with similar urinary excretion of $\mathrm{HMB}^{(14,15)}$. When Ca-HMB was administered, peak plasma HMB levels were $115^{(14)}, 131^{(15)}$ and $131 \mu \mathrm{mol} / \mathrm{l}^{(15)}$, which were comparable to the $154 \mu \mathrm{mol} / 1$ determined in the current study. Previous studies with HMB-FA found the peak plasma HMB levels to be $259^{(15)}$ and $239 \mu \mathrm{mol} / \mathrm{l}^{(15)}$ 

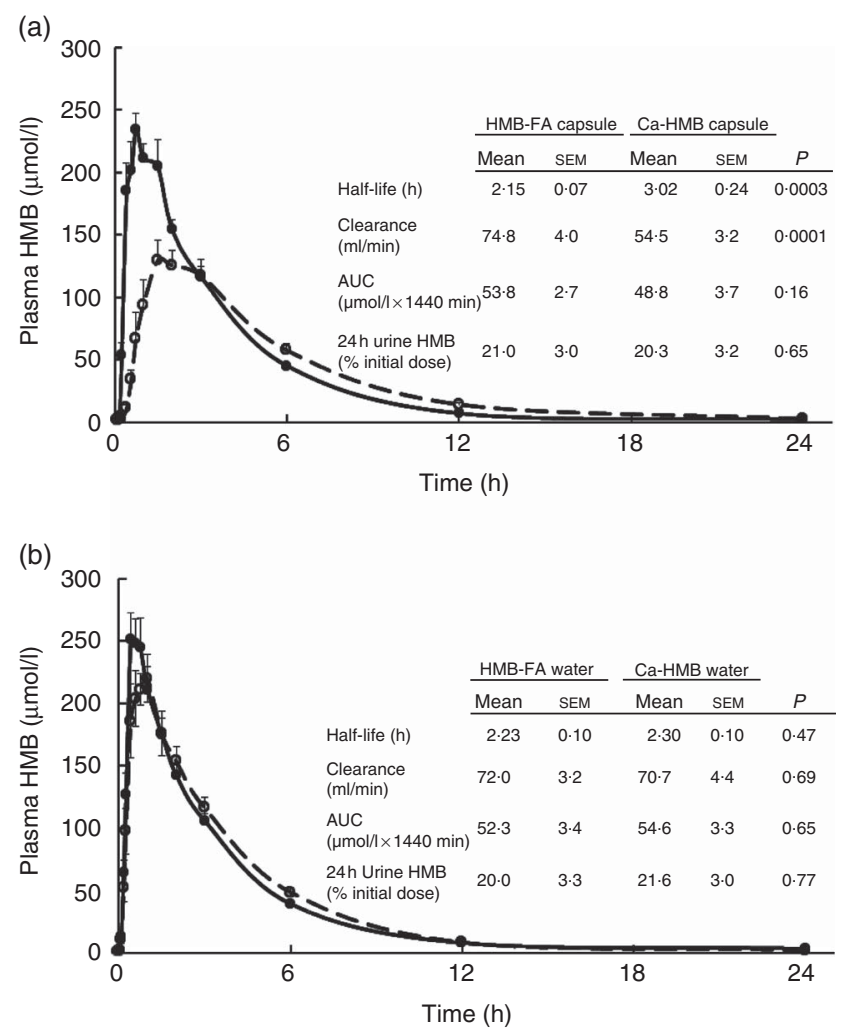

Fig. 2. (a) The $24 \mathrm{~h}$ plasma levels of $\beta$-hydroxy- $\beta$-methylbutyrate (HMB) after administration of either free acid form of HMB (HMB-FA) gelcaps (-๑-) or Ca salt of HMB (Ca-HMB) capsule (- - - -). (b) The $24 \mathrm{~h}$ plasma levels of HMB after administration of either HMB-FA mixed in water (-๑-) or Ca-HMB mixed in water (- - - -). All treatments contained $0.8 \mathrm{~g}$ of HMB. See Fig. 1 for significant differences in plasma HMB concentrations in the initial $3 \mathrm{~h}$. Values are means with their standard error of means for five men and five women. The inset table shows the half-life, clearance, $24 \mathrm{~h}$ AUC and $24 \mathrm{~h}$ urinary excretion of HMB. The $P$ value indicated is for differences between the treatment means.

for the gel form, which was equivalent to the levels, 262 and $270 \mu \mathrm{mol} / 1$ for the gel and gelcap, respectively, in the current study. Similarly, the times to peak HMB level previously determined for Ca-HMB administration were $120^{(14)}, 122^{(15)}$ and 135 $\min ^{(15)}$, which are comparable to the $134 \mathrm{~min}$ in the current study. When HMB-FA was administered in a gel, the times to peak levels were $33^{(15)}$ and $42 \mathrm{~min}^{(15)}$, and in the current study the times to peak level for HMB-FA as a gel and gelcap were 36 and $45 \mathrm{~min}$, respectively. Urinary losses were similar across all studies and dosage forms, and including our present study were between 14 and $25 \%$ of the dosage ${ }^{(14,15)}$. The findings have several practical implications for the average athlete. Although both forms of HMB are equally effective on muscle function and are equally retained by the body over a $24 \mathrm{~h}$ period, the use of HMB-FA allows for more predictive timing of intake of $\mathrm{HMB}$ in relation to the planned exercise, thus achieving better outcomes, as was recently confirmed by Wilson et al. ${ }^{(27)}$

Our human data differ considerably from the recently published data in rodents ${ }^{(33)}$, which reported that Ca-HMB had better availability as measured by peak blood levels when compared with HMB-FA. In that study, the investigators compared Ca-HMB with HMB-FA administration both orally in a liquid suspension and by intravenous injection, ${ }^{(33)}$ and showed that similar amounts of $\mathrm{HMB}$ given as either $\mathrm{Ca}-\mathrm{HMB}$ or HMB-FA resulted in the Ca-HMB having greater peak blood HMB concentrations. There are several concerns with comparison with the rodent study; the most notable is the concern related to species differences. For example, the half-life of $\mathrm{HMB}$ in blood after Ca-HMB dosing is reported as approximately 1, 2 and $3 \mathrm{~h}$ for the rat, pig and sheep, respectively ${ }^{(33-35)}$, compared with humans, with a half-life of 2.4 to $3.2 \mathrm{~h}$ for a $1 \mathrm{~g}$ dosage of $\mathrm{Ca}_{\mathrm{HMB}}{ }^{(14,15)}$. Other concerns relate to the experimental design, and the analytical methods used, as well as methodological differences related to the accuracy of HMB intake. For example, in the rodent study, there is no mention of the methodology for the administration of the oral forms in the methods section of the paper; hence, the method and accuracy of the amount given is in question. In addition, both forms of HMB were dissolved in solutions containing carboxymethylcellulose and Tween 80 with the $\mathrm{pH}$ adjusted to $4 \cdot 5$. This type of solution is likely to affect the bioavailability of the Ca-HMB by increasing its ionisation, dissociation and absorption, thus leading to overestimates of the true pharmacokinetic parameters measured. Last, but not least, there is concern related to the accuracy of the measured plasma HMB levels. The authors used warfarin, which is structurally different from the natural HMB form, as an internal standard for the LC-MS/MS measurements, in contrast to our use of a similar HMB compound, namely $\mathrm{d}_{6}-\mathrm{HMB}$, as an internal standard ${ }^{(36)}$

To reconcile any potential differences attributed to the delivery forms, we carried out a head-to-head comparison of an oral dose of HMB-FA and Ca-HMB given mixed in water instead of in capsule form. The data from the current study confirm our previous findings ${ }^{(15)}$ and demonstrate that even when delivered mixed in water HMB-FA is still superior to $\mathrm{Ca}-\mathrm{HMB}$ in delivering $\mathrm{HMB}$, albeit to lesser degree than when both forms are delivered in capsules. This was quite evident within the first hour of the absorptive period (Fig. 1(b)). In addition, we noted no difference in $24 \mathrm{~h}$ urinary excretion of HMB (Fig. 2(b)), suggesting an earlier and greater tissue availability of $\mathrm{HMB}$ when given in the free acid form.

Our study has few limitations, albeit minor in nature. The first limitation relates to the few number of subjects studied ( $n$ 10); this limitation, however, is countered by the use of the subjects as their own control in a crossover design. Another theoretical limitation may relate to our calculation of the amount of HMB available for tissue utilisation, as the difference between the amount consumed minus the amount excreted in the urine. This assumption would be accurate with additional measurement of HMB oxidation rates, which were not examined in this study. Wilkinson et $a l^{(11)}$ recently demonstrated that after an oral dosage of HMB-FA intramuscular HMB concentrations increased almost 14-fold from baseline at $150 \mathrm{~min}$ after the dose, suggestive of enhanced utilisation of HMB by human muscle following intake of HMB-FA.

In conclusion, the use of the commercially available forms of HMB as either the HMB-FA or Ca-HMB resulted in earlier and increased plasma concentrations, with increased clearance rates, when the HMB was given as HMB-FA. This finding can be used favourably by athletes to gauge their intake of HMB before an exercise bout, as recently observed by Wilson et al. ${ }^{(27)}$. 


\section{Acknowledgements}

The present study was funded by Metabolic Technologies, Inc., Ames, IA.

The authors' contributions were as follows: J. A. R. designed the research. J. A. R., H. F. A., P. Y. K. and R. L. S. conducted the research including sample analysis. J. C. F. Jr analysed the data and wrote the paper. J. A. R. had primary responsibility for final content. All authors read and approved the final manuscript.

J. C. F. Jr and J. A. R. are employed by Metabolic Technologies Inc., Ames, IA. R. L. S. received funds from Metabolic Technologies to conduct the study. H. F. A. and P. Y. K. had no conflicts of interest to declare.

\section{Supplementary material}

For supplementary material/s referred to in this article, please visit http://dx.doi.org/doi:10.1017/S0007114515003050

\section{References}

1. Nissen S, Sharp R, Ray M, et al. (1996) Effect of the leucine metabolite $\beta$-hydroxy $\beta$-methylbutyrate on muscle metabolism during resistance-exercise training. J Appl Physiol 81, 2095-2104.

2. Panton LB, Rathmacher JA, Baier S, et al. (2000) Nutritional supplementation of the leucine metabolite $\beta$-hydroxy $\beta$-methylbutyrate (HMB) during resistance training. Nutr 16, 734-739.

3. Knitter AE, Panton L, Rathmacher JA, et al. (2000) Effects of $\beta$-hydroxy- $\beta$-methylbutyrate on muscle damage following a prolonged run. J Appl Physiol 89, 1340-1344.

4. Wilson GJ, Wilson JM \& Manninen AH (2008) Effects of beta-hydroxy-beta-methylbutyrate (HMB) on exercise performance and body composition across varying levels of age, sex, and training experience: a review. Nutr Metab (Lond) 5, 1.

5. Wilson JM, Fitschen PJ, Campbell B, et al. (2013) International Society of Sports Nutrition Position Stand: beta-hydroxy-betamethylbutyrate (HMB). J Int Soc Sports Nutr 10, 6.

6. Eley HL, Russell ST \& Tisdale MJ (2008) Mechanism of attenuation of muscle protein degradation induced by tumor necrosis factor alpha and angiotensin II by beta-hydroxybeta-methylbutyrate. Am J Physiol Endocrinol Metab 295, E1417-E1426.

7. Smith HJ, Wyke SM \& Tisdale MJ (2004) Mechanism of the attenuation of proteolysis-inducing factor stimulated protein degradation in muscle by beta-hydroxy-beta-methylbutyrate. Cancer Res 64, 8731-8735.

8. Smith HJ, Mukerji P \& Tisdale MJ (2005) Attenuation of proteasome-induced proteolysis in skeletal muscle by $\beta$-hydroxy- $\beta$-methylbutyrate in cancer-induced muscle loss. Cancer Res 65, 277-283.

9. Eley HL, Russell ST, Baxter JH, et al. (2007) Signaling pathways initiated by $\beta$-hydroxy- $\beta$-methylbutyrate to attenuate the depression of protein synthesis in skeletal muscle in response to cachectic stimuli. Am J Physiol Endocrinol Metab 293, E923-E931.

10. Eley HL, Russell ST \& Tisdale MJ (2008) Attenuation of depression of muscle protein synthesis induced by lipopolysaccharide, tumor necrosis factor and angiotensin II by $\beta$-hydroxy- $\beta$-methylbutyrate. Am J Physiol Endocrinol Metab 295, E1409-E1416.
11. Wilkinson DJ, Hossain T, Hill DS, et al. (2013) Effects of leucine and its metabolite beta-hydroxy-beta-methylbutyrate on human skeletal muscle protein metabolism. J Physiol 591 , 2911-2923.

12. Wilson JM, Kim JS, Lee SR, et al. (2009) Acute and timing effects of beta-hydroxy-beta-methylbutyrate (HMB) on indirect markers of skeletal muscle damage. Nutr Metab (Lond) 6, 6 .

13. Wilson JM, Lowery RP, Joy JM, et al. (2013) ) $\beta$-Hydroxy$\beta$-methylbutyrate free acid reduces markers of exerciseinduced muscle damage and improves recovery in resistance-trained men. BrJ Nutr 110, 538-544.

14. Vukovich MD, Slater G, Macchi MB, et al. (2001) ) $\beta$-Hydroxy$\beta$-methylbutyrate (HMB) kinetics and the influence of glucose ingestion in humans. J Nutr Biochem 12, 631-639.

15. Fuller JC Jr, Sharp RL, Angus HF, et al. (2011) Free acid gel form of $\beta$-hydroxy- $\beta$-methylbutyrate (HMB) improves HMB clearance from plasma in humans compared to the calcium HMB salt. Br J Nutr 105, 367-372.

16. Dreyer HC, Fujita S, Cadenas JG, et al. (2006) Resistance exercise increases AMPK activity and reduces 4E-BP1 phosphorylation and protein synthesis in human skeletal muscle. J Physiol 576, 613-624.

17. Phillips SM, Tipton KD, Aarsland A, et al. (1997) Mixed muscle protein synthesis and breakdown after resistance exercise in humans. Am J Physiol 273, E99-E107.

18. Kerksick C, Harvey $\mathrm{T}$, Stout J, et al. (2008) International Society of Sports Nutrition Position Stand: nutrient timing. J Int Soc Sports Nutr 5, 17.

19. American College of Sports Medicine, American Dietetic Association \& Dieticians of Canada (2000) Joint position statement: nutrition and athletic performance. Med Sci Sports Exerc 32, 2130-2145.

20. Coyle EF, Coggan AR, Hemmert MK, et al. (1985) Substrate usage during prolonged exercise following a preexercise meal. J Appl Physiol (1985) 59, 429-433.

21. Tatara MR (2009) Effect of beta-hydroxy-beta-methylbutyrate (HMB) administration on volumetric bone mineral density, and morphometric and mechanical properties of tibia in male turkeys. J Anim Physiol Anim Nutr (Berl) 93, 669-677.

22. Tatara MR, Krupski W, Tymczyna B, et al. (2012) Effects of combined maternal administration with alpha-ketoglutarate (AKG) and beta-hydroxy-beta-methylbutyrate (HMB) on prenatal programming of skeletal properties in the offspring. Nutr Metab (Lond) 9, 39.

23. Tatara MR, Sliwa E, Krupski W, et al. (2008) 3-Hydroxy-3methylbutyrate administration diminishes fundectomyinduced osteopenia of the lumbar spine in pigs. Nutr $\mathbf{2 4}$, $753-760$.

24. Tatara MR (2008) Neonatal programming of skeletal development in sheep is mediated by somatotrophic axis function. Exp Physiol 93, 763-772.

25. Gerlinger-Romero F, Guimaraes-Ferreira L, Giannocco G, et al. (2011) Chronic supplementation of beta-hydroxy-beta methylbutyrate $(\mathrm{HM} \beta)$ increases the activity of the GH/IGF-I axis and induces hyperinsulinemia in rats. Growth Horm IGF Res 21, 57-62.

26. Townsend JR, Hoffman JR, Gonzalez AM, et al. (2015) Effects of beta-hydroxy-beta-methylbutyrate free acid ingestion and resistance exercise on the acute endocrine response. Int $J$ Endocrinol 2015, article ID 856708.

27. Wilson JM, Lowery RP, Joy JM, et al. (2014) The effects of 12 weeks of beta-hydroxy-beta-methylbutyrate free acid supplementation on muscle mass, strength, and power in resistance trained individuals: a randomized, double-blind, placebo-controlled study. Eur J Appl Physiol 114, 1217-1227. 
28. Nissen S, Van Koevering M \& Webb D (1990) Analysis of $\beta$-hydroxy- $\beta$-methyl butyrate in plasma by gas chromatography and mass spectrometry. Anal Biochem 188, $17-19$.

29. Urso R, Blardi P \& Giorgi G (2002) A short introduction to pharmacokinetics. Eur Rev Med Pharmacol Sci 6, 33-44.

30. Guyton AC \& Hall JE (2006) The body fluid compartments: extracellular and intracellular fluids: interstitial fluid and edema. In Textbook of Medical Physiology, pp. 291-306. Philadelphia, PA: W B Saunders Company.

31. Thalhammer F, Schenk P, Burgmann H, et al. (1998) Singledose pharmacokinetics of meropenem during continuous venovenous hemofiltration. Antimicrob Agents Chemother 42, 2417-2420
32. SAS Institute Inc. (1985) SAS User's Guide: Statistics, 5th ed. Cary, NC: SAS Institute Inc.

33. Shreeram S, Johns PW, Subramaniam S, et al. (2014) The relative bioavailability of the calcium salt of beta-hydroxybeta-methylbutyrate is greater than that of the free fatty acid form in rats. $J$ Nutr 144, 1549-1555.

34. Nissen SL \& Abumrad NN (1997) Nutritional role of the leucine metabolite $\beta$-hydroxy- $\beta$-methylbutyrate (HMB). J Nutr Biochem 8, 300-311

35. Van Koevering M \& Nissen S (1992) Oxidation of leucine and $\alpha$-ketoisocaproate to $\beta$-hydroxy- $\beta$-methylbutyrate in vivo. Am J Physiol (Endocrinol Metab) 262, E27-E31.

36. Nissen S, Van Koevering M \& Webb D (1990) Analysis of $\beta$-hydroxy- $\beta$-methyl butyrate in plasma by gas chromatography and mass spectrometry. Anal Biochem 188, 17-19. 